\title{
Effect of chronic obstructive pulmonary disease combined with ventilator-associated pneumonia on patient outcomes: A systematic review and meta-analysis
}

\author{
MINGYUAN YIN ${ }^{1}$ and MEIRONG LIU ${ }^{2}$ \\ Departments of ${ }^{1}$ Nursing, and ${ }^{2}$ Outpatient Administration, Hunan Provincial People's Hospital, \\ The First Affiliated Hospital of Hunan Normal University, Changsha, Hunan 410001, P.R. China
}

Received June 25, 2020; Accepted September 11, 2020

DOI: $10.3892 /$ etm.2020.9403

\begin{abstract}
The purpose of the present systematic review and meta-analysis was to uncover whether chronic obstructive pulmonary disease (COPD) as a co-morbidity influences outcomes of patients with ventilator-associated pneumonia (VAP) compared to VAP alone and whether the development of VAP in patients with COPD is associated with poor outcome in comparison to COPD alone. An electronic search of the PubMed, Embase, Scopus, BioMed Central, CENTRAL and Google scholar databases for all types of studies assessing the influence of COPD on outcomes of patients with VAP and vice versa was performed. A total of 7 studies were included. Of these, 3 studies assessed the impact of COPD on outcomes of patients with VAP. Meta-analysis indicated that the presence of COPD significantly increased the mortality of patients with VAP [risk ratio (RR): 1.37, 95\% CI: 1.14-1.65, $\mathrm{I}^{2}=3 \%$, $\mathrm{P}=0.007]$. The analysis failed to demonstrate any significant effect of COPD on the duration of mechanical ventilation in patients with VAP [mean difference (MD): $2.37,95 \%$ CI: -5.77 to $\left.10.50, \mathrm{I}^{2}=38 \%, \mathrm{P}=0.57\right]$. However, the duration of the intensive care unit (ICU) stay was significantly longer in patients with COPD and VAP as compared with that of patients with VAP without COPD (MD: 5.53, 95\% CI: 0.73-10.33, $\mathrm{I}^{2}=0 \%$, $\mathrm{P}=0.02$ ). A total of 4 studies assessed the impact of VAP on outcomes of patients with COPD. Meta-analysis indicated that the presence of VAP significantly increased mortality of patients with COPD (RR: $1.52,95 \%$ CI: $1.08-2.12, \mathrm{I}^{2}=71 \%$, $\mathrm{P}=0.02$ ). Pooled analysis indicated that the presence of VAP in patients with COPD significantly increased the duration of mechanical ventilation (MD: 13.73, 95\% CI: 7.86-19.61,
\end{abstract}

Correspondence to: Mrs. Meirong Liu, Department of Outpatient Administration, Hunan Provincial People's Hospital, The First Affiliated Hospital of Hunan Normal University, 89 Guhan Road, Changsha, Hunan 410001, P.R. China

E-mail:1my_dr@163.com

Key words: chronic obstructive lung disease, pneumonia, mortality, mechanical ventilation
$\left.\mathrm{I}^{2}=92 \%, \mathrm{P}<0.00001\right)$ and the duration of the ICU stay as compared to patients with COPD but without VAP (MD: 17.36, 95\% CI: 9.55-25.17, $\left.\mathrm{I}^{2}=90 \%, \mathrm{P}<0.0001\right)$. To conclude, within the limitations of the study, the present results indicated that the combination of COPD and VAP significantly increased patient mortality and the duration of ICU stay. The development of VAP in patients with COPD also significantly increased the duration of mechanical ventilation. Further case-matched studies are required to assess the influence of the severity of COPD in combination with VAP on patient outcomes.

\section{Introduction}

Chronic obstructive pulmonary disease (COPD) affects $>65$ million individuals worldwide and is to become the third most common cause of death worldwide by the year 2030 (1). The disease is characterized by limitation of airflow and arises from an abnormal inflammatory response of the lungs to noxious gas particles (2). COPD is also a major risk factor for the development of nosocomial lower respiratory tract infections, as the patient's immune system may be weakened by prolonged corticosteroid use and reduced microbial clearance (3). During the natural course of the disease, exacerbations and infections are common in patients with COPD, the management of which requires assisted ventilation and hospitalization (4).

Patients requiring prolonged duration of mechanical ventilation in the intensive care unit (ICU) have a particular risk of developing ventilator-associated pneumonia (VAP) (5). An estimated $10-20 \%$ of patients receiving mechanical ventilation for $>24 \mathrm{~h}$ are diagnosed with VAP (6). VAP is not only associated with increased healthcare costs but also significantly contributes to increased in-ICU morbidity and mortality (6).

Since both COPD and VAP adversely affect lung function, a combination of both disorders may have serious effects on patient outcomes. The inter-relation between COPD and VAP, however, has not been thoroughly analyzed in the literature. In a narrative review, Koulenti et al (7) assessed the current literature on the effects of VAP on patients with COPD and vice versa. To the best of our knowledge, to date, no meta-analysis 
has analyzed outcomes of patients with COPD and VAP. Therefore, the purpose of the present review was to answer the following questions by pooling data from the literature: i) whether COPD as a co-morbidity influences outcomes of patients with VAP as compared to VAP alone; and ii) whether the development of VAP in patients with COPD is associated with unfavorable outcomes as compared with that in patients not developing VAP.

\section{Materials and methods}

Search strategy. This review was conducted following the guidelines of the Preferred Reporting Items for Systematic Reviews and Meta-analyses statement (8). A total of two reviewers (MY and ML) independently performed an electronic search of the PubMed, Embase, Scopus, BioMed Central, CENTRAL and Google scholar databases. The last search was carried out on 15th April 2020. Both MeSH terms and free-text key words were used for searching relevant articles. The following key words were used: 'Chronic obstructive pulmonary disease', 'chronic obstructive lung disease', 'chronic obstructive airway disease', 'pneumonia', 'ventilator associated pneumonia', 'ventilator-associated pneumonia', 'mortality', 'death', 'intensive care' and 'hospital stay'. The reviewers screened the search results initially by their titles and abstracts for each database. After identifying potentially pertinent articles, full texts of the articles were extracted. Both the reviewers assessed individual articles based on the inclusion and exclusion criteria. Any disagreements were resolved by discussion. After screening, the bibliography of included studies and review articles on the subject were hand-searched for any missed references.

Inclusion criteria. Both prospective and retrospective observational studies were considered for this review. For the first part, i.e. to assess the impact of COPD on outcomes of VAP, the following inclusion criteria were used: i) studies conducted on patients with VAP admitted to an ICU; ii) study participants received mechanical ventilation for $>48 \mathrm{~h}$ for any medical or post-surgical care; iii) patients receiving only non-invasive ventilation were excluded; iv) the cohort was divided into patients with COPD and those without COPD and assess at least one of the three outcomes: Mortality, duration of mechanical ventilation and length of ICU stay. For the second part, i.e. to assess the impact of VAP on outcomes of patients with COPD, the following inclusion criteria were used: i) studies on patients with COPD admitted to an ICU and requiring mechanical ventilation for $>48 \mathrm{~h}$; ii) the cohort was divided into patients with VAP and without VAP and assess at least one of the three outcomes: Mortality, duration of mechanical ventilation and length of ICU stay. For both groups, single-arm studies and studies not reporting relevant data were excluded.

Data extraction and risk of bias analysis. After mutual agreement regarding the inclusion of studies, the two reviewers extracted data from the included studies independently. For the first part, data including the first author's name, publication year, study type, sample size, demographic details, reason for ICU admission, presence of co-morbidities and shock, previous use of steroids and antibiotics, disease severity scores, number of patients with VAP due to multi-drug resistant bacteria, partial pressure of oxygen/fraction of inspired oxygen $\left(\mathrm{PO}_{2} / \mathrm{FiO}_{2}\right)$, clinical pulmonary infection score (CPIS) and study outcomes were extracted. For the second part, data including the name of the first author, publication year, study type, sample size, demographic details, presence of co-morbidities, simplified acute physiology score II (SAPS II), previous use of steroids and antibiotics, number of patients with VAP due to multi-drug resistant bacteria and study outcomes were extracted.

Outcomes of the analysis were the same for both parts of the review. The primary outcome of interest was mortality. Secondary outcomes of interest were duration of mechanical ventilation and length of ICU stay. Data were fed into meta-analysis software and cross-checked for correctness. In the case of missing outcome data, the corresponding author was contacted via email.

The risk of a bias assessment tool for non-randomized studies was used to analyze the quality of included studies (9). Two reviewers (MY and ML) independently assessed the quality of studies and any disagreements were resolved after discussion. Studies were assessed for the following items: Selection of participants, confounding variables, measurement of intervention, blinding of outcome assessment, incomplete outcome data and selective outcome reporting.

Statistical analysis. Review Manager (version 5.3; Cochrane Collaboration) was used for the meta-analysis. Categorical data of mortality were pooled to obtain the risk ratio (RR) with $95 \%$ CI. Since the duration of mechanical ventilation and length of ICU stay were continuous outcomes, they were summarized using the mean difference (MD) with $95 \%$ CI. If data were presented as the median and interquartile range, the mean and standard deviation scores were calculated using the method developed by Wan et al (10). A random-effects model was used to calculate the pooled effect size for all analyses. Heterogeneity was assessed using the $\mathrm{I}^{2}$ statistic. $\mathrm{I}^{2}$ values of $25-50 \%$ represented low, values of $50-75 \%$ medium and $>75 \%$ represented substantial heterogeneity. Due to the inclusion of $<10$ studies in the review, funnel plots were not used to assess publication bias.

\section{Results}

Study search and selection. A study flow chart is presented in Fig. 1. A total of 13 articles were extracted for full-text analysis. A total of six studies were excluded, as they did not fulfill the inclusion criteria. Finally, 7 studies were included in this systematic review and meta-analysis (1,11-16).

Influence of COPD on outcomes of VAP. A total of 3 studies $(1,15,16)$ assessed the impact of COPD on outcomes of VAP patients. Details of these studies are presented in Table I. All of them were prospective observational studies. The sample size varied from 30 to 65 patients in the COPD arm and 126 to 308 patients in the non-COPD arm. Patients were admitted to the ICUs for both medical and surgical reasons. The included studies did not report any statistically significant differences in patient co-morbidities between COPD and non-COPD patients, except for that by Rouze et al (1), which reported a significant difference in 


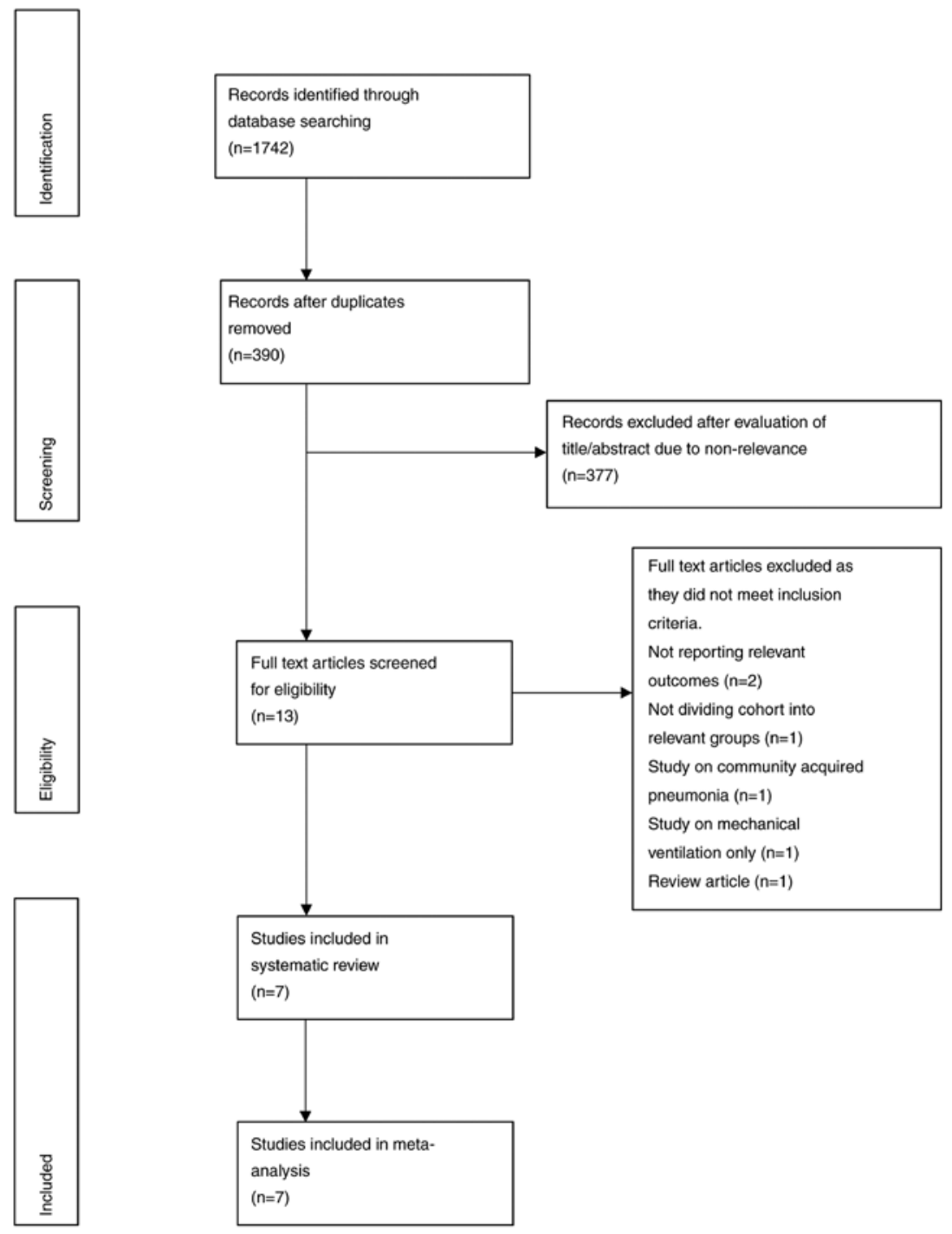

Figure 1. Study flow chart.

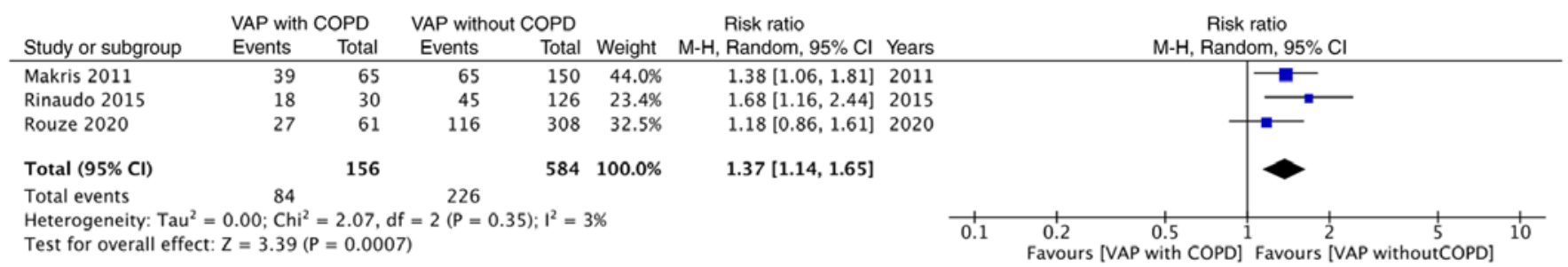

Figure 2. Forest plot for VAP with COPD vs. VAP without COPD for the outcome 'mortality'. COPD, chronic obstructive pulmonary disease; VAP, ventilator-associated pneumonia; M-H, Mantel-Haentzel; df, degrees of freedom.

the number of diabetics. Furthermore, disease severity was significantly higher in the COPD group in the study of Makris et al (16). The studies did not report any statistically significant difference in previous use of steroids and antibiotics, presence of shock and $\mathrm{PO}_{2} / \mathrm{FiO}_{2}$ between the two groups, except for the study of Makris et al (16), wherein there was a higher incidence of steroid use in patients with COPD. The CPIS was not significantly different between COPD and non-COPD patients in all three studies. Definitions of COPD and VAP in the included studies are presented in Table II.
The definitions of COPD were based on standard American Thoracic Society/European Respiratory Society criteria (17) and Global Initiative for Chronic Obstructive Lung Disease (GOLD) criteria (4) in the included studies. Furthermore, two studies $(1,16)$ also used microbiological cultures for confirmation of VAP.

Mortality data were reported by all three studies. Meta-analysis of data from 156 COPD patients and 584 non-COPD patients indicated that the presence of COPD significantly increased the risk of mortality of patients with 
Table I. Characteristics of studies assessing the impact of COPD on outcomes of VAP.

\begin{tabular}{|c|c|c|c|c|c|c|}
\hline \multirow[b]{3}{*}{ Parameter } & \multicolumn{6}{|c|}{ Author, year (reference) } \\
\hline & \multicolumn{2}{|c|}{ Makris, 2011 (16) } & \multicolumn{2}{|c|}{ Rinaudo, 2015 (15) } & \multicolumn{2}{|c|}{ Rouzé, 2020 (1) } \\
\hline & COPD & Non-COPD & COPD & Non-COPD & COPD & Non-COPD \\
\hline Sample size & 65 & 150 & 30 & 126 & 61 & 308 \\
\hline Mean age, years & $68 \pm 11$ & $58 \pm 17$ & $71 \pm 9$ & $63 \pm 17$ & NR & NR \\
\hline \multicolumn{7}{|l|}{ Reason for ICU admission } \\
\hline Medical & 54 & 103 & 26 & 95 & NR & NR \\
\hline Surgical & 11 & 47 & 4 & 31 & NR & NR \\
\hline \multicolumn{7}{|l|}{ Co-morbidities } \\
\hline Liver cirrhosis & 3 & 3 & 2 & 8 & 5 & 18 \\
\hline Cardiac disease & 21 & 21 & 16 & 37 & - & - \\
\hline Renal failure & 4 & 4 & 4 & 8 & - & - \\
\hline Diabetes & 7 & 7 & 8 & 30 & $18^{\mathrm{a}}$ & $51^{\mathrm{a}}$ \\
\hline Alcoholism & - & - & - & - & 11 & 38 \\
\hline Respiratory failure & - & - & - & - & 9 & 25 \\
\hline Heart failure & - & - & - & - & 4 & 15 \\
\hline \multirow[t]{2}{*}{ Severity scores } & SAPS II & SAPS II & SOFA & SOFA & SOFA & SOFA \\
\hline & $47 \pm 16$ & $53 \pm 18^{a}$ & $7.5 \pm 3.3$ & $7.5 \pm 3.2$ & $8.4 \pm 3.3$ & $7.9 \pm 3.6$ \\
\hline Presence of shock & 19 & 39 & 13 & 62 & 5 & 17 \\
\hline Previous use of steroids & 17 & $6^{\mathrm{a}}$ & 16 & 51 & NR & NR \\
\hline Prior use of antibiotics & 37 & 61 & 26 & 100 & NR & NR \\
\hline VAP due to MDR bacteria & 39 & 86 & NR & NR & NR & NR \\
\hline $\mathrm{PO}_{2} / \mathrm{FiO}_{2}$ & $207 \pm 109$ & $227 \pm 105$ & $199 \pm 64$ & $211 \pm 78$ & NR & NR \\
\hline CPIS & $5.8 \pm 1.6$ & $5.2 \pm 1.7$ & $6.6 \pm 1.3$ & $6.7 \pm 1.5$ & $6(5-8)$ & $7(5-8)$ \\
\hline
\end{tabular}

All listed studies are prospective studies. Data are presented as the count (n), or the mean \pm SD. ${ }^{\mathrm{a}}<0.05$ vs. COPD as shown in the respective studies. Surgical reasons refers to patients admitted to ICU after surgery for monitoring. ICU, intensive care unit; CPIS, clinical pulmonary infection score; $\mathrm{COPD}$, chronic obstructive pulmonary disease; $\mathrm{FiO}_{2}$, fraction of inspired oxygen; VAP, ventilator-associated pneumonia; NR, not reported; $\mathrm{PO}_{2}$, partial pressure of oxygen; SOFA, sequential organ failure assessment; MDR, multidrug resistance; SAPS II, simplified acute physiology score II.

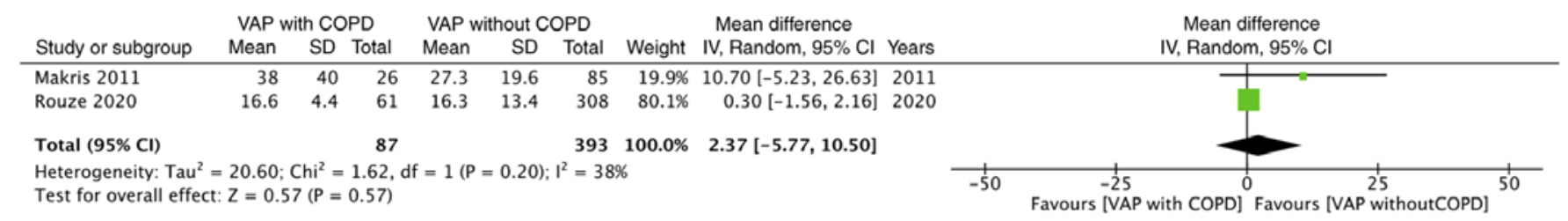

Figure 3. Forest plot for VAP with COPD vs. VAP without COPD for the outcome 'duration of mechanical ventilation'. COPD, chronic obstructive pulmonary disease; VAP, ventilator-associated pneumonia; SD, standard deviation; IV, inverse variance; df, degrees of freedom.

VAP (RR: $1.37,95 \%$ CI: $1.14-1.65, \mathrm{I}^{2}=3 \%, \mathrm{P}=0.007$; Fig. 2 ). Data on the duration of mechanical ventilation and length of ICU stay were reported by two studies. The present analysis failed to demonstrate any significant effect of COPD on the duration of mechanical ventilation in patients with VAP (MD: 2.37, 95\% CI: -5.77 to $10.50, \mathrm{I}^{2}=38 \%, \mathrm{P}=0.57$; Fig. 3). However, the duration of ICU stay was significantly longer in patients with COPD and VAP as compared to that in patients with VAP without COPD (MD: 5.53, 95\% CI: 0.73-10.33, $\mathrm{I}^{2}=0 \%$, $\mathrm{P}=0.02$; Fig. 4).
Influence of VAP on outcomes of COPD. A total of 4 studies (11-14) assessed the impact of VAP on outcomes of patients with COPD. Details of these studies are presented in Table III. Of these, 3 were prospective studies (11-13), while one was a retrospective study (14). The sample size of the VAP arm varied from 35 to 92 patients and the sample size of the non-VAP arm varied from 60 to 318 . There was no significant difference in the mean age between the study groups. None of the studies reported any difference in patient co-morbidities and SAPS II scores. Definitions of COPD and 
Table II. Definitions used by studies assessing the impact of COPD on outcomes of VAP.

\begin{tabular}{|c|c|c|c|}
\hline Study & Definition of COPD & Definition of VAP & (Refs. \\
\hline Makris et al & $\begin{array}{l}\text { According to American } \\
\text { Thoracic Society/European } \\
\text { Respiratory Society criteria }\end{array}$ & $\begin{array}{l}\text { Presence of new or progressive radiographic infiltrate associated } \\
\text { with two of the three of the following criteria: i) temperature } \\
>38.5 \text { or }<36.5^{\circ} \mathrm{C} \text {; ii) leukocyte count }>10,000 \text { or }<1,500 / \mathrm{ml} \text {; } \\
\text { iii) purulent tracheal aspirate. In addition, a positive tracheal } \\
\text { aspirate culture }\left(\geq 10^{6} \mathrm{CFU} / \mathrm{ml}\right) \text { or bronchoalveolar lavage culture } \\
\left(\geq 10^{4} \mathrm{CFU} / \mathrm{ml}\right) \text { was required to confirm the diagnosis of VAP. }\end{array}$ & (16) \\
\hline Rinaudo et al & $\begin{array}{l}\text { According to American } \\
\text { Thoracic Society/European } \\
\text { Respiratory Society criteria }\end{array}$ & $\begin{array}{l}\text { Presence of new or progressive radiographic infiltrate associated } \\
\text { with two of the three of the following criteria: i) temperature of } \\
>38.5 \text { or }<36.5^{\circ} \mathrm{C} \text {; ii) leucocyte count }>12,000 \text { or }<4,000 \text { cells } / \mu 1 \text {; } \\
\text { iii) purulent secretions. }\end{array}$ & $(15)$ \\
\hline Rouzé et al & $\begin{array}{l}\text { According to Global Initiative } \\
\text { for Chronic Obstructive Lung } \\
\text { Disease criteria }\end{array}$ & $\begin{array}{l}\text { Presence of new or progressive radiographic infiltrate associated } \\
\text { with two of the following three criteria: i) temperature of }>38.5 \\
\text { or }<36.5^{\circ} \mathrm{C} \text {; ii) leucocyte count }>12,000 \text { or }<4,000 \text { cells } / \mu 1 \text {; } \\
\text { iii) purulent secretions. In addition, all episodes of infection } \\
\text { required microbiological confirmation, with the isolation in the } \\
\text { endotracheal aspirate of at least } 10^{5} \mathrm{CFU} / \mathrm{ml} \text { or in } \\
\text { bronchoalveolar lavage of at least } 10^{4} \mathrm{CFU} / \mathrm{ml} \text {. }\end{array}$ & (1) \\
\hline
\end{tabular}

CFU, colony-forming units; COPD, chronic obstructive pulmonary disease; ICU, intensive care unit; VAP, ventilator-associated pneumonia.

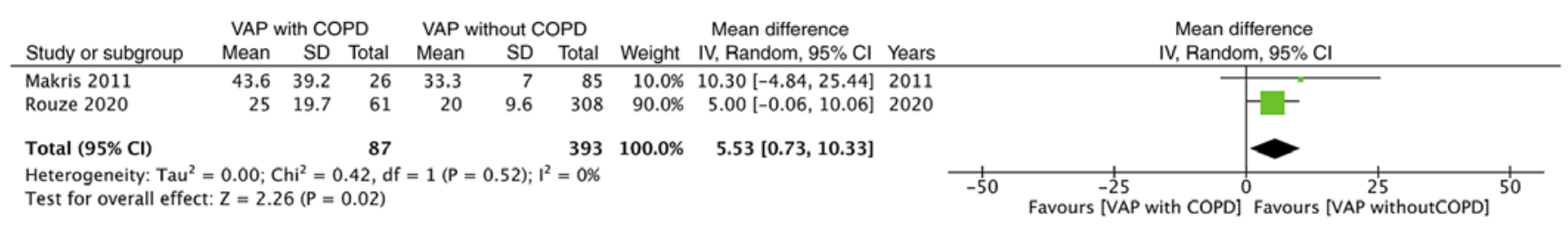

Figure 4. Forest plot for VAP with COPD vs. VAP without COPD for the outcome 'duration of ICU stay'. COPD, chronic obstructive pulmonary disease; VAP, ventilator-associated pneumonia; SD, standard deviation; IV, inverse variance; df, degrees of freedom.

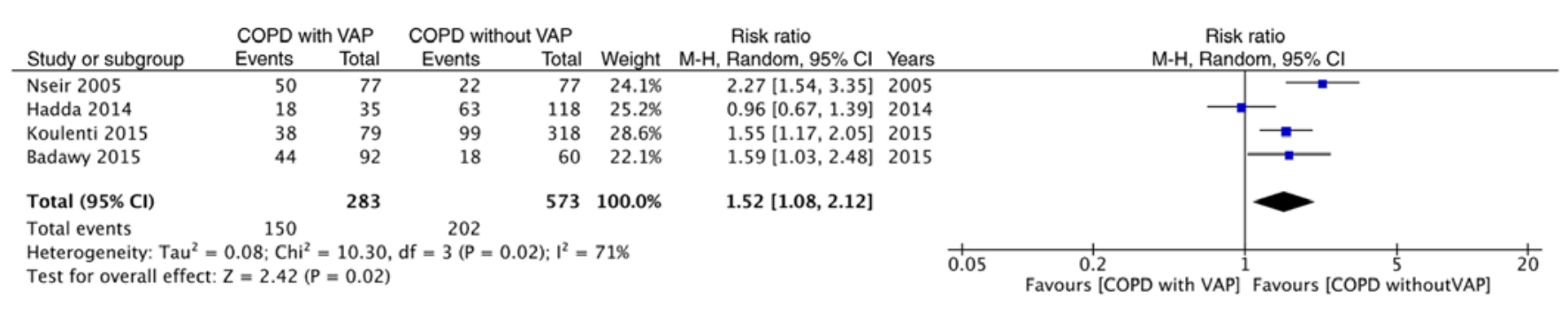

Figure 5. Forest plot for COPD with VAP vs. COPD without VAP for the outcome 'mortality'. COPD, chronic obstructive pulmonary disease; VAP, ventilator-associated pneumonia; M-H, Mantel-Haentzel; df, degrees of freedom.

VAP used by the included studies are presented in Table IV. A total of 2 studies $(13,14)$ did not define the diagnostic criteria for COPD and 2 studies $(11,14)$ used microbiological culture for diagnosing VAP.

Data on mortality were reported by all four studies. The present meta-analysis with data of 283 patients with VAP and 573 patients without VAP indicated that the presence of VAP significantly increased the mortality of patients with COPD (RR: 1.52, 95\% CI: 1.08-2.12, $\mathrm{I}^{2}=71 \%$, P=0.02; Fig. 5). Data on secondary outcomes were also reported by all four studies. Pooled analysis indicated that the presence of VAP in patients with COPD significantly increased the duration of mechanical ventilation (MD: 13.73 , 95\% CI: 7.86-19.61, $\mathrm{I}^{2}=92 \%, \mathrm{P}<0.00001$; Fig. 6). In addition, patients with VAP and COPD had a significantly longer ICU stay as compared to patients with COPD without VAP (MD: 17.36, 95\% CI: 9.55-25.17, $\mathrm{I}^{2}=90 \%, \mathrm{P}<0.0001$; Fig. 7).

Risk of bias analysis. The results of the authors' judgement of the risk of bias in individual studies are presented in 


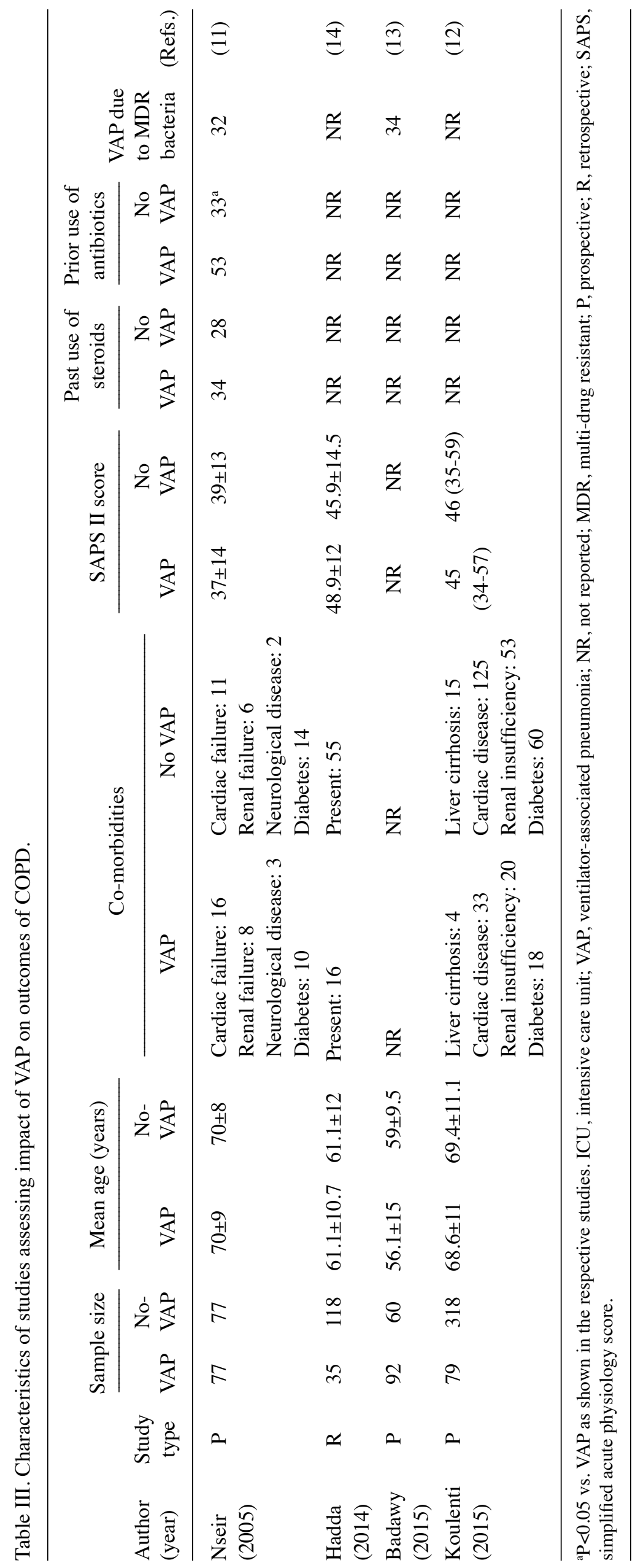


Table IV. Definitions used by studies assessing impact of VAP on outcomes of COPD.

\begin{tabular}{|c|c|c|c|}
\hline Study & Definition of COPD & Definition of VAP & (Refs \\
\hline Nseir et al & $\begin{array}{l}\text { According to American Thoracic } \\
\text { Society criteria }\end{array}$ & $\begin{array}{l}\text { Presence of new or progressive radiographic } \\
\text { infiltrate associated with two of the following three } \\
\text { criteria: i) temperature }>38.5 \text { or }<36.5^{\circ} \mathrm{C} \text {; ii) } \\
\text { leukocyte count }>10,000 \text { or }<1,500 / \mathrm{ml} \text {; iii) purulent } \\
\text { tracheal aspirate. In addition, a positive tracheal } \\
\text { aspirate culture }\left(\geq 10^{6} \mathrm{CFU} / \mathrm{ml}\right) \text {. }\end{array}$ & (11) \\
\hline Hadda et al & NS & $\begin{array}{l}\text { Radiographic features suggestive of pneumonia plus } \\
\text { presence of any two of the following: fever, } \\
\text { leukocytosis, purulent or change in the character of } \\
\text { endotracheal aspirate, isolation of the pathogen } \\
\text { from of endotracheal aspirate or other respiratory } \\
\text { specimen and hypoxemia. }\end{array}$ & (14) \\
\hline Badawy et al & NS & $\begin{array}{l}\text { Based on the American College of Chest Physicians } \\
\text { criteria as an association of a new or progressive } \\
\text { consolidation on chest radiology plus at least two of } \\
\text { the following variables: fever with temperature } \\
>38^{\circ} \mathrm{C} \text {, leukocytosis or leukopenia and purulent } \\
\text { secretions. }\end{array}$ & (13) \\
\hline Koulenti et al & $\begin{array}{l}\text { Presence of COPD was recorded based } \\
\text { on pulmonary function tests prior to ICU } \\
\text { admission where available, or on clinical } \\
\text { criteria, medical history (including } \\
\text { significant smoke exposure, previous use } \\
\text { of respiratory medications) and evidence } \\
\text { of hyper-inflation on chest radiograph. }\end{array}$ & $\begin{array}{l}\text { Pulmonary infection arising } \geq 48 \mathrm{~h} \text { after } \\
\text { endotracheal intubation with no evidence of } \\
\text { pneumonia at the time of intubation or the diagnosis } \\
\text { of a new pulmonary infection if the initial } \\
\text { admission to the ICU was for pneumonia. }\end{array}$ & (12) \\
\hline
\end{tabular}

CFU, colony-forming units; COPD, chronic obstructive pulmonary disease; ICU, intensive care unit; VAP, ventilator-associated pneumonia; NS, not specified.

Table V. Risk of bias in included studies.

\begin{tabular}{|c|c|c|c|c|c|c|c|}
\hline Study & $\begin{array}{l}\text { Selection of } \\
\text { participants }\end{array}$ & $\begin{array}{c}\text { Confounding } \\
\text { variables }\end{array}$ & $\begin{array}{l}\text { Measurement } \\
\text { of intervention }\end{array}$ & $\begin{array}{c}\text { Blinding } \\
\text { of outcome } \\
\text { assessment }\end{array}$ & $\begin{array}{l}\text { Incomplete } \\
\text { outcome data }\end{array}$ & $\begin{array}{l}\text { Selective } \\
\text { outcome } \\
\text { reporting }\end{array}$ & (Refs.) \\
\hline Makris et al & Low risk & High risk & Low risk & High risk & Low risk & Unclear risk & (16) \\
\hline Rinaudo et al & Low risk & High risk & Low risk & High risk & Low risk & Unclear risk & (15) \\
\hline Rouzé et al & Low risk & High risk & Low risk & High risk & Low risk & Unclear risk & $(1)$ \\
\hline Nseir et al & Low risk & High risk & Low risk & High risk & Low risk & Unclear risk & (11) \\
\hline Hadda et al & Low risk & High risk & Low risk & High risk & Low risk & Unclear risk & (14) \\
\hline Badawy et al & Low risk & High risk & Low risk & High risk & Low risk & Unclear risk & (13) \\
\hline Koulenti et al & Low risk & High risk & Low risk & High risk & Low risk & Unclear risk & (12) \\
\hline
\end{tabular}

Table V. All studies included both study and control cases from the same hospital setups and therefore had low risk of bias for 'selection of patients'. None of the studies took into account all possible confounding factors. Selection bias could not be assessed as no prior protocols were available for comparison. The overall quality of the studies was moderate.

\section{Discussion}

The results of the present systematic review and meta-analysis suggested a significant inter-relation of COPD and VAP regarding patient outcomes. The presence of COPD as a co-morbidity in patients with VAP was significantly associated with a higher odds of mortality and increased duration of ICU 


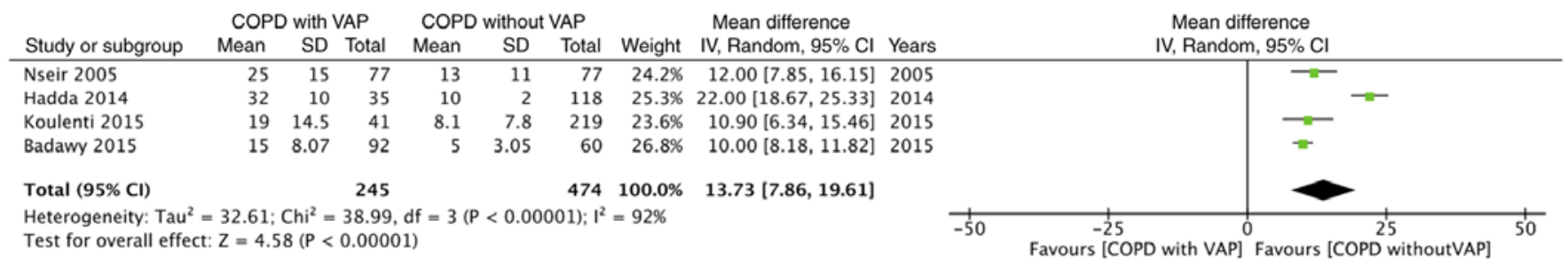

Figure 6. Forest plot for COPD with VAP vs. COPD without VAP for the outcome 'duration of mechanical ventilation'. COPD, chronic obstructive pulmonary disease; VAP, ventilator-associated pneumonia; SD, standard deviation; IV, inverse variance; df, degrees of freedom.

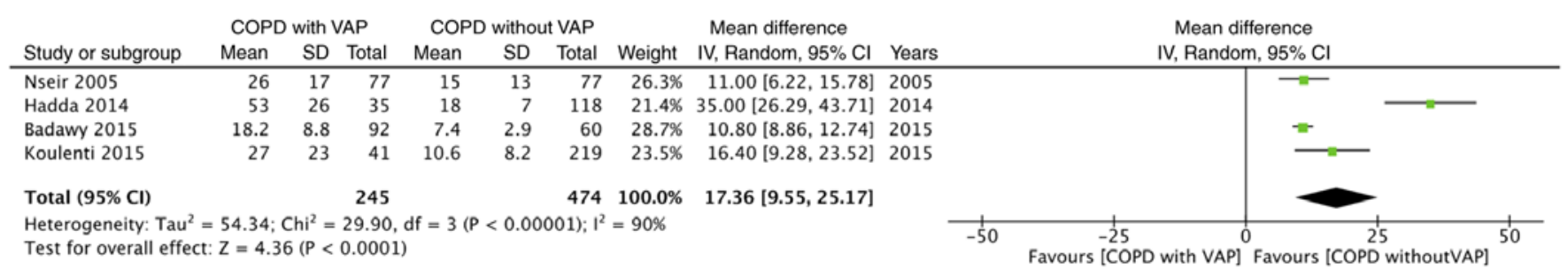

Figure 7. Forest plot for COPD with VAP vs. COPD without VAP for the outcome 'duration of ICU stay'. COPD, chronic obstructive pulmonary disease; VAP, ventilator-associated pneumonia; SD, standard deviation; IV, inverse variance; df, degrees of freedom.

stay as compared with those of patients without COPD. On the other hand, the analysis also indicated that the development of VAP in a cohort of patients with COPD admitted to the ICU significantly increased mortality, the duration of mechanical ventilation and length of ICU stay as compared with those of patients with COPD but without VAP.

According to previous studies, COPD is a commonco-morbidity in patients with VAP $(18,19)$. However, it was demonstrated that the presence of COPD is not associated with a higher incidence of VAP as compared with that of patients without COPD $(1,12)$. Over the last decades, several studies have attempted to assess the impact of COPD on the outcomes of patients with VAP. However, many of these studies did not take baseline differences and disease severity in COPD and non-COPD patients into account while comparing mortality. A study by Rello et al (20) on 129 patients with VAP, including 24 patients with COPD, reported significantly higher mortality of $33 \%$ in patients with COPD as compared to $9 \%$ in patients without COPD. However, after taking into account other confounding factors such as age $>45$ years, corticosteroid use, presence of shock, hospital stay $>9$ days and prior use of antibiotics, the authors did not identify any significant impact of COPD on mortality of patients with VAP. By contrast, in another study of 78 patients with VAP, Torres et al (21) reported that COPD was a significant risk factor for mortality on multivariate analysis. In view of this ambiguity in the literature, in the present meta-analysis, only those studies which divided their cohort into two groups based on the presence of COPD and reported disease severity were pooled. The analysis indicated that the presence of COPD as a co-morbidity leads to a 1.37-fold increased risk of mortality in patients with VAP. The reason for this increased risk of death may be attributed to several factors including the adverse influence of COPD on baseline respiratory function, nutritional status of patients with COPD or previous long-term use of corticosteroids $(17,22)$. An autopsy study by Scott et al (23) indicated increased injury and collagen deposition in diaphragms of patients with COPD. This is thought to reduce respiratory muscle function in patients with COPD, which may contribute to higher mortality $(16,23)$. The reduced respiratory function of patients with COPD has also been reported to impact outcomes of patients undergoing mechanical ventilation without the development of VAP. A study by Rodríguez et al (24) on 235 patients reported that the presence of non-exacerbated COPD significantly increased mortality of patients undergoing mechanical ventilation. Studies have also indicated that patients with COPD developing VAP have a high presence of multi-drug resistant (MDR) bacteria $(12,16,25)$. Koulenti et al (12) reported a significantly higher number of Pseudomonas aeruginosa isolates in patients with COPD developing VAP as compared to non-COPD patients. Patients with VAP due to MDR bacteria are at a higher risk of receiving incorrect antibiotic treatment, which may increase the mortality of such individuals (16).

The present analysis on the influence of COPD as a comorbidity on the duration of mechanical ventilation and length of ICU stay only pooled two studies. While no difference in the duration of mechanical ventilation was identified between VAP patients with and without COPD, the presence of COPD was indicated to significantly increase the duration of ICU stay. The association of disease severity with these secondary outcomes was assessed by Makris et al (16), who indicated that the duration of mechanical ventilation and length of ICU stay were significantly longer for GOLD stage IV COPD vs. non-COPD VAP patients, but not for GOLD stage I-III COPD patients. However, the authors did not assess the same relationship for VAP-associated mortality. An important factor that may also influence the incidence and outcomes of VAP patients is the primary cause of ICU admission. Specific groups of patients such as those with neurological disorders or neurosurgical patients may be at a higher risk of developing VAP and subsequent adverse outcomes. This may be due to several reasons such as increased risk of aspiration, use of intravenous anesthetics and sedatives or prolonged duration of ventilation (26). A meta-analysis by Melsen et al (27) indicated 
that the attributable mortality of VAP differs with different sub-groups of patients with higher rates for surgical patients as compared to medical or trauma patients. Exact details of the primary cause of ICU admission were not available in the studies included in the review. Lack of sufficient data preclude us from drawing strong conclusions on the influence of COPD on secondary outcomes.

Patients with COPD frequently encounter exacerbations during the course of the disease, which require respiratory support and hospitalization (28). Non-invasive ventilation is usually the standard of care during such periods, but in certain cases, endotracheal intubation may be required to reduce mortality (4). Invasive mechanical ventilation may, however, be complicated by VAP. The incidence of VAP in intubated patients with COPD may vary from $18.6 \%$ to as high as $60 \%$ and may affect patient outcomes $(12,13)$. The association between the development of VAP and increased morbidity and mortality for ICU patients has been assessed by several studies, but with heterogenous patient populations and inconsistent results (29-31). In the second part of the present analysis, it was indicated that patients with COPD developing VAP during the course of their management had a 1.52-fold increased risk of mortality as compared with that of patients not developing VAP. On analysis of the forest plots in the present study, it was indicated that with the exception of one study (14), all other studies reported a higher risk of mortality with VAP in patients with COPD. In the study of Hadda et al (14), the overall mortality rate in the cohort was high (51\%), which was attributed to high disease severity of the sample, presence of type 2 respiratory failure and hypoxemia. It should be noted that the study by Hadda et al (14) was the only retrospective study in the present meta-analysis, while the remaining studies were prospective studies. The present results also indicated that the development of VAP in patients with COPD significantly increased the duration of mechanical ventilation by a mean of 13 days and prolonged the ICU stay by 17 days. Statistically significant results for these secondary outcomes were reported by all four studies included in the present systematic review.

It is important to note that several other confounding factors may influence the outcomes of patients with COPD developing VAP. First, numerous co-morbidities may co-exist in patients with COPD, which can affect mortality, duration of mechanical ventilation and length of ICU stay (32). A meta-analysis of 37 studies by Singanayagam et al (33) reported that low body mass index, cardiac failure, diabetes mellitus, ischemic heart disease and malignancy are significantly associated with increased mortality in patients with acute exacerbations of COPD. It is also reported that the presence of more than one co-morbidity may double the risk of COPD-associated mortality (34). Furthermore, similar co-morbidities are known to also influence outcomes of VAP (18). Thus, the results of the present analysis may have been confounded by these variables. Among the four studies included in the present review, data on co-morbidities were reported by all except that by Badawy et al (13). However, none of them reported any statistically significant differences between their study cohorts. In addition, the management of COPD may vary depending on the severity of the disease. The management protocol may include short- or long-acting muscarinic antagonists, $\beta$-agonists, inhaled corticosteroids (ICS), supplemental oxygen therapy or combinations of these drugs (35). It was postulated that chronic ICS use in COPD may diminish the patient's defenses, leading to a rise in opportunistic infections such as VAP (12). Of the included studies, no study assessing the influence of VAP on COPD outcomes analyzed the influence of ICS on patient mortality. The study by Koulenti et al (12) included data on chronic steroid use in the definition of immunosuppression. However, in their analysis, immunosuppression was not indicated to be a significant factor increasing the prevalence of VAP in patients with COPD. The literature on the role of ICS on outcomes of community-acquired pneumonia is conflicting. Studies have reported that patients with COPD receiving long-term ICS may have a higher prevalence of community-acquired pneumonia but its effects on patient mortality remain unclear $(36,37)$.

The results of the present study should be interpreted with the following limitations. First, only a limited number of studies were available for meta-analysis. In the pooled analysis of two outcome measures, data from only two studies were analyzed. The lack of adequate data may have introduced bias in the overall results. The overall quality of studies was also not high. Furthermore, the inherent bias of the observational studies may have skewed the outcomes. There were differences in the included studies with respect to the exact diagnostic criteria of VAP with few studies utilizing microbiological cultures. In addition, not all studies reported complete data on baseline characteristics of the study cohorts. Furthermore, data on the severity of COPD were not available for any study and therefore, the influence of the severity of COPD on the outcomes could not be assessed. As another limitation, the heterogeneity in the present meta-analysis for assessing the influence of VAP on outcomes of COPD was high. This may be attributed to differences in the study settings and study populations among the included studies. However, due to the limited number of studies, it was not possible to explore the source of heterogeneity by a sub-group or meta-regression analysis. Finally, treatment protocols vary with patients as well as hospital setups. Therefore, with these limited data, it may not be possible to generalize the results of the present review.

In spite of these limitations, the present study was the first meta-analysis to assess the inter-relationship of the effects of VAP and COPD on patient outcomes and the results may have implications for clinical practice. Based on the present results, it may be suggested that prompt and thorough management is recommended for patients with COPD developing VAP. Such patients should be considered as having a high risk of mortality. There is also a requirement for rigorous measures to prevent the development of VAP in patients with COPD.

To conclude, within the limitations of the present study, the results indicated that the combination of COPD and VAP significantly increases patient mortality and the duration of ICU stay. The development of VAP in patients with COPD also significantly increased the duration of mechanical ventilation. Further case-matched studies are required to assess the relationship of the severity of COPD combined with VAP on patient outcomes. 


\section{Acknowledgements}

Not applicable.

\section{Funding}

No funding was received.

\section{Availability of data and materials}

The datasets used and/or analyzed during the current study are available from the corresponding author on reasonable request.

\section{Authors' contributions}

MY conceived and designed the study. MY and ML collected the data and performed the literature search. MY was involved in the writing of the manuscript. All authors read and approved the final manuscript.

\section{Ethics approval and consent to participate}

Not applicable.

\section{Patient consent for publication}

Not applicable.

\section{Competing interests}

The authors declare that they have no competing interests.

\section{References}

1. Rouzé A, Boddaert P, Martin-loeches I, Povoa P, Rodriguez A, Ramdane N, Salluh J, Houard M and Nseir S: Impact of chronic obstructive pulmonary disease on incidence, microbiology and outcome of ventilator-associated lower respiratory tract infections. Microorganisms 8: 165, 2020.

2. Tsiligianni I, Metting E, Van Der Molen T, Chavannes N and Kocks J: Morning and night symptoms in primary care COPD patients: A cross-sectional and longitudinal study. An UNLOCK study from the IPCRG. NPJ Prim Care Respir Med 26: 16040 , 2016 .

3. Tantucci C and Pini L: Inhaled corticosteroids in COPD: Trying to make a long story short. Int J Chron Obstruct Pulmon Dis 15: 821-829, 2020.

4. Rabe KF, Hurd S, Anzueto A, Barnes PJ, Buist SA, Calverley P, Fukuchi Y, Jenkins C, Rodriguez-Roisin R, van Weel C, et al: Global strategy for the diagnosis, management, and prevention of chronic obstructive pulmonary disease: GOLD executive summary. Am J Respir Crit Care Med 176: 532-555, 2007.

5. Kallet RH: Ventilator bundles in transition: From prevention of ventilator-associated pneumonia to prevention of ventilator-associated events. Respir Care 64: 994-1006, 2019.

6. Hellyer TP, Ewan V, Wilson P and Simpson AJ: The Intensive Care Society recommended bundle of interventions for the prevention of ventilator-associated pneumonia. J Intensive Care Soc 17: 238-243, 2016.

7. Koulenti D, Parisella FR, Xu E, Lipman J and Rello J: The relationship between ventilator-associated pneumonia and chronic obstructive pulmonary disease: what is the current evidence? Eur J Clin Microbiol Infect Dis 38: 637-647, 2019.

8. Moher D, Liberati A, Tetzlaff J and Altman DG; PRISMA Group: Preferred reporting items for systematic reviews and meta-analyses: The PRISMA Statement. PLoS Med 6: e1000097, 2009.
9. Kim SY, Park JE, Lee YJ, Seo HJ, Sheen SS, Hahn S, Jang BH and Son HJ: Testing a tool for assessing the risk of bias for nonrandomized studies showed moderate reliability and promising validity. J Clin Epidemiol 66: 408-14, 2013.

10. Wan X, Wang W, Liu J and Tong T: Estimating the sample mean and standard deviation from the sample size, median, range and/or interquartile range 14: 135, 2014.

11. Nseir S, Di Pompeo C, Soubrier S, Cavestri B, Jozefowicz E, Saulnier F and Durocher A: Impact of ventilator-associated pneumonia on outcome in patients with COPD. Chest 128: 1650-1656, 2005.

12. Koulenti D, Blot S, Dulhunty JM, Papazian L, Martin-Loeches I, Dimopoulos G, Brun-Buisson C, Nauwynck M, Putensen C, Sole-Violan J, et al: COPD patients with ventilator-associated pneumonia: Implications for management. Eur J Clin Microbiol Infect Dis 34: 2403-2411, 2015.

13. Badawy MS, Omar HM, Mohamdien HA, Moktar EA and Deaf EA: Evaluation of risk factors of ventilator associated pneumonia on outcome of acute exacerbation of chronic obstructive pulmonary disease. Egypt J Chest Dis Tuberc 64: 799-803, 2015.

14. Hadda V, Khilnani GC, Dubey G, Nallan R, Kumar G and Guleria R: Impact of ventilator associated pneumonia on outcome in patients with chronic obstructive pulmonary disease exacerbation. Lung India 31: 4-8, 2014.

15. Rinaudo M, Ferrer M, Terraneo S, De Rosa F, Peralta R, Fernández-Barat L, Li Bassi G and Torres A: Impact of COPD in the outcome of ICU-Acquired pneumonia with and without previous intubation. Chest 147: 1530-1538, 2015.

16. Makris D, Desrousseaux B, Zakynthinos E, Durocher A and Nseir S: The impact of COPD on ICU mortality in patients with ventilator-associated pneumonia. Respir Med 105: 1022-1029, 2011.

17. Celli BR and MacNee W; ATS/ERS Task Force: Standards for the diagnosis and treatment of patients with COPD: A summary of the ATS/ERS position paper. Eur Respir J 23: 932-946, 2004.

18. Wu D, Wu C, Zhang S and Zhong Y: Risk factors of ventilator-associated pneumonia in critically III patients. Front Pharmacol 10: 482, 2019.

19. van der Kooi TII, Boshuizen H, Wille JC, de Greeff SC, van Dissel JT, Schoffelen AF and van Gaalen RD: Using flexible methods to determine risk factors for ventilator-associated pneumonia in the Netherlands. PLoS One 14: e0218372, 2019.

20. Rello J, Ausina V, Ricart M, Castella J and Prats G: Impact of previous antimicrobial therapy on the etiology and outcome of ventilator-associated pneumonia. Chest 104: 1230-1235, 1993.

21. Torres A, Aznar R, Gatell JM, Jiménez P, González J, Ferrer A, Celis R and Rodriguez-Roisin R: Incidence, risk, and prognosis factors of nosocomial pneumonia in mechanically ventilated patients. Am Rev Respir Dis 142: 523-528, 1990.

22. Ranzani OT, Ferrer M, Esperatti M, Giunta V, Bassi GL, Carvalho CR and Torres A: Association between systemic corticosteroids and outcomes of intensive care unit-acquired pneumonia. Crit Care Med 40: 2552-2561, 2012.

23. Scott A, Wang X, Road J and Reid W: Increased injury and intramuscular collagen of the diaphragm in COPD: Autopsy observations. Eur Respir J 27: 51-59, 2006.

24. Rodríguez A, Lisboa T, Solé-Violán J, Gómez F, Roca O, Trefler S, Gea J, Masclans JR and Rello J: Impact of nonexacerbated COPD on mortality in critically Ill patients. Chest 139: 1354-1360, 2011.

25. Moghoofei M, Azimzadeh Jamalkandi S, Moein M, Salimian J and Ahmadi A: Bacterial infections in acute exacerbation of chronic obstructive pulmonary disease: A systematic review and meta-analysis. Infection 48: 19-35, 2020.

26. Wu VKS, Fong C, Walters AM and Lele AV: Prevalence, clinical characteristics, and outcomes related to ventilator-associated events in neurocritically Ill patients. Neurocrit Care 33: 499-507, 2020.

27. Melsen WG, Rovers MM, Groenwold RH, Bergmans DC, Camus C, Bauer TT, Hanisch EW, Klarin B, Koeman M, Krueger WA, et al: Attributable mortality of ventilator-associated pneumonia: A meta-analysis of individual patient data from randomised prevention studies. Lancet Infect Dis 13: 665-671, 2013.

28. Kong CW and Wilkinson TM: Predicting and preventing hospital readmission for exacerbations of COPD. ERJ Open Res 6: 00325-02019, 2020.

29. Balasubramanian P and Tullu MS: Study of ventilator-associated pneumonia in a pediatric intensive care Unit. Indian J Pediatr 81: 1182-1186, 2014. 
30. Karakuzu Z, Iscimen R, Akalin H, Girgin NK, Kahveci F and Sinirtas M: Prognostic risk factors in ventilator-associated pneumonia. Med Sci Monit 24: 1321-1328, 2018.

31. Ranjan N, Chaudhary U, Chaudhry D and Ranjan KP: Ventilator-associated pneumonia in a tertiary care intensive care unit: Analysis of incidence, risk factors and mortality. Indian J Crit Care Med 18: 200-204, 2014.

32. Crisafulli E, Barbeta E, Ielpo A and Torres A: Management of severe acute exacerbations of COPD: An updated narrative review. Multidiscip Respir Med 13: 36, 2018.

33. Singanayagam A, Schembri S and Chalmers JD: Predictors of mortality in hospitalized adults with acute exacerbation of chronic obstructive pulmonary disease: A systematic review and meta-analysis. Ann Am Thorac Soc 10: 81-89, 2013.

34. Recio Iglesias J, Díez-Manglano J, López García F, Díaz Peromingo JA, Almagro P and Varela Aguilar JM: Management of the COPD patient with comorbidities: An experts recommendation document. Int J Chron Obstruct Pulmon Dis 15 1015-1037, 2020.
35. Crawley A, Laubscher T, Muddiman P and Kosar L: Pharmacologic management of COPD: Breadth of products for encouraging a breath of air. Can Fam Physician 62: 410-414, 2016.

36. Yamauchi Y, Yasunaga H, Hasegawa W, Sakamoto Y, Takeshima H, Jo T, Matsui H, Fushimi K and Nagase T: Effect of outpatient therapy with inhaled corticosteroids on decreasing in-hospital mortality from pneumonia in patients with COPD. Int J Chron Obstruct Pulmon Dis 11: 1403-1411, 2016.

37. Sibila O, Soto-Gomez N and Restrepo MI: The risk and outcomes of pneumonia in patients on inhaled corticosteroids. Pulm Pharmacol Ther 32: 130-136, 2015.

(i) () $(-)$ This work is licensed under a Creative Commons International (CC BY-NC-ND 4.0) License. 